\title{
Sustainable Product Service Systems Design: Tools for Strategic Analysis
}

\author{
SANTOS, A. ${ }^{1, a}$ \\ ${ }^{1}$ Paraná Federal University, Design Department, Rua General Carneiro, 460, sl 717, Curitiba, Brazil
}

\begin{abstract}
The present paper discusses the tools for phase of Strategic Analysis for the process of Sustainable Product-Service System Design. It explores the cumulative experience obtained at the Design \& Sustainability Research Center of UFPR, on case studies developed with companies on the period between 2006 to 2016. When compared with the MSDS Method the case studies presented a stronger emphasis on tools derived from administration (ex: Ansoff matrix, BCG matrix, Canvas, SWOT chart, Slack matrix, Polarity Diagram) and, very importantly, from the service design community (ex: bluepring, customer journey, touchpoint matrix).
\end{abstract}

Keywords. PSS Design, Strategic Analysis, Service Design, Strategic Design, Tools, Method

\section{Introduction}

Moving our society to more sustainable patterns of consumption and production has several possible strategies, from the mere revision of material flows on the supply chain or redesign of existing products to the design of product-service systems or changes in life style. Such strategies often demand and result on technological innovations (e.g.: new materials, new ICT protocols) as well as social innovations (e.g.: initiatives of creative communities), or a combination of both on socio-technical innovations (e.g.: distributed approaches for production).

There is a reasonable consolidated body of knowledge on methods and tools for designing artefacts, which is widely used across the Design schools around the world. Such knowledge is increasingly being repositioned and redirected towards sustainability goals. However, when dealing with more complex issues such as product-service systems or new life style scenarios the body of knowledge is still evolving. A clear indicator of such situation is the reduced amount of didactic material available to lecturers on Design schools.

It is within this context that it was implemented the LeNSin Project (the International Learning Network of networks on Sustainability (2015-2018)). It is an EUsupported (ERASMUS+) project involving 36 universities from Europe, Asia, Africa, South America and Central America, aiming at the promotion of a new generation of designers (and design educators) capable to effectively contribute to the transition towards a sustainable society for all.

The main ambition of LeNSin Project is the internationalisation, intercultural cross-fertilisation and accessibility of higher education on Design for
Sustainability (DfS). The project focuses on Sustainable Product-Service Systems (S.PSS) and Distributed Economies (DE) - considering both as promising models to couple environmental protection with social equity, cohesion and economic prosperity - applied in different contexts around the world. LeNSin connects a multipolar network of Higher Education Institutions adopting and promoting a learning-by-sharing knowledge generation and dissemination, with an open and copyleft ethos (LeNSin, 2017).

In order to contribute with the goals of the LeNSin Project this article presents a set of propositions on Methods and Tools for Product Service System Design, focusing on the Strategic Phase. The propositions come after several case studies developed at the Design \& Sustainability Research Centre, in partnership with different companies profiles, on the period between 2005 and 2016. The paper compares the propositions against the methods and tools proposed by VanHalen, Vezzoli and Wimmer (2005) and PDPNet reference model described in Amaral \& Rozenfeld (2007).

\section{THE STRATEGY PHASE IN PSS DESIGN}

\subsection{The PDPNet Model Perspective}

At the Design \& Sustainability Research Center the general structure for the development of product-service systems adopts the propositions of the PDPNet reference model. This model was devised by a network of research groups and professionals from the field of product development management, depicting best practices for managing the product development processes. It is equivalent to a Body of Knowledge (BOK) on product

\footnotetext{
a Prof. Aguinaldo dos Santos: asantos@ufpr.br
} 
development, arranged in phases. It presents phases and activities and several practices and methods available in the field, integrating the best available practices and elucidating them in detail irrespective of the company's evolution level (AMARAL \& ROZENFELD, 2007).

PDPNet is divided into three macro-phases: predevelopment, development and postdevelopment. Each macro-phase is divided into phases, activities and tasks. Figure 1 represents macro-phases, phases and support processes.

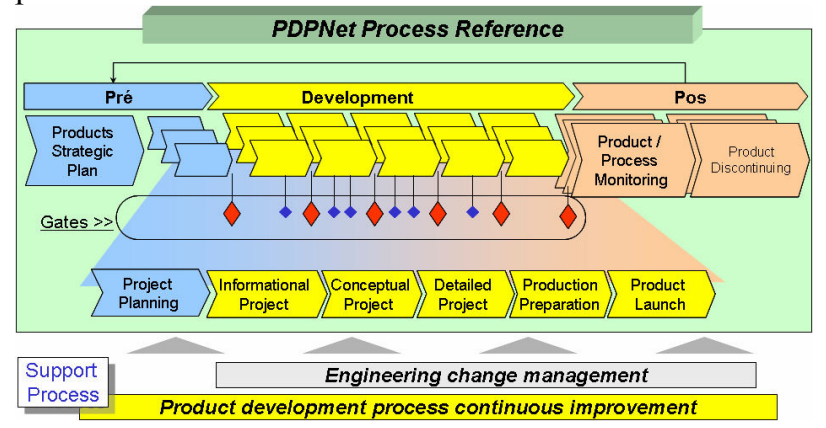

Figure 1. Macro-phases and phases of PDPNet process reference model (source: Amaral \& Rozenfeld, 2007).

The Strategic Phase on the PDPNet Model occurs on the "Pre-development macro-phase (blue)", linking the projects developed by the organization and its goals. In the case of companies this phase deals with the Corporation or Business Unit Strategic Plan deployments on project portfolio, with the evaluation and track of selected projects.

\subsection{The MSDS Model Perspective}

According to Vezzoli et al., (2014) the MSDS (Method for System Design for Sustainability) was devised to support and orient the entire process of system innovation development towards sustainability. It was conceived for designers and companies but is also appropriate for public institutions and NGOs. It can be used by an individual designer or by a wider design team. In all cases special attention has been paid to facilitating co-designing processes both within the organisation itself (between people from different disciplinary backgrounds) and outside, bringing different socio-economic actors and end-users into play.

The method is organised in stages, processes and sub-processes. Like the PDPNet Model it is characterised by a flexible modular structure so that it can easily be adapted to the specific needs of designers /companies and to diverse design contexts and conditions. Its modular structure includes procedures, tools, allowing to choose which dimension of sustainability to operate and the integration of design tools that have not been specifically developed for it. It is also possible to modify existing activities or add new ones according to the particular requirements of the design project (VEZZOLI et al, 2014):.

The basic structure of MSDS consists of four main stages: a) Strategic analysis; b) Exploring opportunities
-Designing system concepts; c) Designing (and engineering) a system. A Communication stage can be added, across the others, of drawing up documents to report on the sustainability characteristics of the solution designed (VEZZOLI et al, 2014).

The aim of the Strategic Analysis phase is to obtain the information necessary to facilitate the generation of sustainable system innovation ideas. According to Vezzoli et al., (2014) in order to achieve this goal the method requires analysis of the project proposers; outline the intervention context; the context of reference; the carrying structure of the system; cases of sustainable best practice; sustainability of existing system; priorities for the design intervention in view of sustainability; sufficiency need assessment.

The aim of the first part of the method is to collect and process all the background information necessary to the generation of a set of potentially sustainable ideas. On one hand the goal is to understand the existing situation and find out more about the project proposers, the socio-economic context in which they operate and the dynamics (socio-economic, technological and cultural macro-trends) that influence that context; on the other hand, the goal is to process information by which to steer the designing process towards the generation of promising solutions (VEZZOLI et al, 2014).

a) Defining the context of intervention and analysing the project proposers: regardless the type or organization, the aim of this activity is first and foremost to define the scope of the design intervention, or rather the demand for well-being to be met (e.g. provide clean clothes). At this point the characteristics of the project proposers are examined carefully: their 'mission', their main areas of expertise, their strength and weaknesses, opportunities and threats, in relation to the area of intervention. In addition, particularly if the proposer is a company, the value chain will be analysed to understand how this is structured, what are the key stakeholders, what problems (environmental, socio-ethic and economic) may be met. Key questions include (VEZZOLI et al, 2014):

-What is the demand to be met?

-What are the key areas of expertise of the project promoters?

-What are their main strengths and weaknesses?

-Who are the main actors? What is the relationship between/among them?

-What are the main environmental, socio-ethical and economic problems associated with the value chain?

-What is the value for the client and/or end user?

b) Analysing the context of reference: the aim of this activity is to analyse the context, or rather the sociotechnical regime, of which the new innovation will become a part. First of all, the structure of the production and consumption system (the scope of intervention) is analysed: what actors come into play (companies, institutions, NGOs, consumers etc.) and what the relationships are between them, as well as what specific dynamics (technological, cultural, economic and 
regulatory) characterise the system itself. Special attention is also paid to current and potential competitors (analysing their characteristics and offers) and to clients and/or end users (analysing their needs). Key questions include (extracted from VEZZOLI et al, 2014):

- How is the entire production and consumption chain structured in relation to the scope of intervention (satisfaction unit)? Who are the main actors (public and private) and their respective interests?

-What are the technological, cultural and regulatory dynamics influencing, or of potential influence to, the characteristics of the production and consumption chain?

-Who are the main competitors? What are their offers and how do these differ from those of the project proposers?

-Who are the potential clients and end users? What are their needs? Are their needs satisfied?

c) Analysing the carrying structure of the system: the aim of this activity is to identify and analyse the general macro-trends (social, economic and technological) that lie behind the reference context. It is important to understand these in order to understand what potentially influences the context (or socio-technical regime) that will be the object of the intervention. Key question include (VEZZOLI et al, 2014):

-What are the main social, economic and technological macro-trends? How may these influence the reference context and consequently the design options?

d) Analysing cases of excellence for sustainability (best practices): the aim of this activity is to analyse in detail cases of excellence (not necessarily concerning the area of intervention) that could act as a stimulus during the generation of ideas. The result will be a document summarising the offer in each case of excellence, interactions with the user, the offer producers and providers, and its sustainability characteristics. The supporting tools include the SDO toolkit for analysing sustainability characteristics, the System Map and the Interaction table for the general case description. Key questions on this activity include (VEZZOLI et al, 2014)::

-What is the offer, in terms of products and services? How does the user interact with the offer?

-Who are the actors in the offer system? What are their intentions?

-What are the environmental, socio-ethical and economic advantages?

e) Analyse sustainability of existing system and determine priorities for the design intervention in view of sustainability: the aim of this activity is to analyse the existing context from an environmental, socio-ethical and economic point of view in order to identify the design priorities (in other words, where it is most important to intervene in order to reduce the environmental, socio-ethical and economic impact to the greatest degree). This operation is fundamental to steering the design process towards the solutions that are the most able to foster sustainability. The result will be a document summarising the environmental, socio-ethical and economic analysis and defining design priorities. One supporting tool for this process is the SDO toolkit (Sustainable Design Orienting Toolkit). Key questions include (VEZZOLI et al, 2014):

-What is the situation in the existing context regarding environmental, socio-ethical and economic sustainability?

-What are the design priorities for each dimension of sustainability?

f) Sufficiency need assessment: the aim of this activity is to thoroughly assess the existing situation with respect to the Sufficiency Economy Philosophy (SEP)'s three components: Reasonableness, Moderation and Self-Immunity. It is the first stage in the Design for a Sufficiency Economy (DSE) approach: planning/design and implementation processes aimed at achieving sufficient living and sustainable well-being for individuals, communities and societies. The assessment should yield robust knowledge on the current situation: who the stakeholders are within the system; their behaviours and interactions; and how the existing system operates. It is also essential to detect any recent changes that may lead to a particular future trend. The most crucial task is to assess whether the conducts (both of users and product/service providers) in the existing situation are aligned with the principles of the SEP. The result will be a document that clarifies the current sufficiency level and illustrates if the existing system displays a balance (or imbalance) in the four dimensions of People, Planet, Profit and Technology, an imbalance implying weak aspects that need to be addressed. Tools for this step include task analysis, DSE Checklists (Part 1), and Evaluation of the Sufficiency Levels (Part 2) (VEZZOLI et al, 2014).

\section{RESEARCH METHOD}

The present research uses "case study" as the main research strategy in investigating the scope of tools on Strategic Phase of PSS Design. Yin (2008) defines "case study" as an empirical investigation into contemporary phenomenon operating in a real-life context. It is particularly valuable when there is not a clear delimitation between the phenomenon and the context itself. Thus, this research strategy is suitable explore tools that contribute to provide the strategic direction to PSS Design because it incorporates all the normal uncertain conditions faced by practitioners (Robson, 2016; Yin, 2008).

\section{RESULTS \& ANALYSIS}

A total of five case studies have been analysed (see next Table), covering a period of ten year of research projects focused on the issue of PSS design. These case studies included both small as well as large organizations, dealing with a variety of themes, from rainwater harvesting to low income houses (Tigre) to the provision of office working spaces (Globusiness). 
Table 1. General Profile of the Case Studies.

\begin{tabular}{|l|l|l|l|}
\hline Partner & Period & PSS Type & Focus \\
\hline Volkswagen & $2006-2008$ & Result-Oriented & Packaging \\
\hline Globusiness & $2008-2010$ & Result-Oriented & Working space \\
\hline Tigre & $2010-2011$ & Product-Oriented & Rainwater Harvesting \\
\hline Cohapar & $2011-2014$ & Product-Oriented & Light \\
\hline Whirlpool & $2012-2014$ & Use-Oriented & Laundry \\
\hline Accord & $2014-2016$ & Product-Oriented & Light \\
\hline
\end{tabular}

Most case studies have shown the need, event among large companies, of developing an "elicitation" of the company strategy. Indeed, in the Brazilian context it is not uncommon to find companies that do not have a strategic planning process or deficient communication of the current strategic plan. For that regard the projects at NDS/UFPR has adopted the set of tools presented below, aiming at enhance the understanding on the current long term directions of the company:

- Questionnaire for Strategic Elicitation focusing on identifying the organization core business, its mission, principles and strategic objectives.

- SWOT matrix complements the questionnaire with an internal perspective on the Strength and Weakness as well as an external perspective on the Opportunities and Threats to the organization;

- BCG matrix (or Growth-Share matrix): a chart that help to analyze the portfolio of a given business unit, categorizing products/services in "Cash cows" (high market share in a slow-growing industry), "Dogs" (low market share in a mature, slowgrowing industry), "Question marks" (operating with a low market share in a high-growth market) and "Stars" (high market share in a fast-growing industry).

- SLACK matrix (or importance $\mathrm{x}$ performance matrix): it uses a list of competitive criteria such as quality, flexibility, cost, etc, comparing the organization performance vis a vis its importance for each criteria;

- ANSOFF Matrix: helps to understand the growth strategy of the organization, with quadrants on Market penetration, Market development, Product development and Diversification;

- Porter's 5 Forces Model: analysis of barriers and bargain power of the organization regarding Clients, Potential Entrants, Direct Competitors, Suppliers and Substitutes;

System Map (see Figure below) remains in all case studies as a key tool to support the identification of key stakeholders and their material, information, money and work flows, for the provision of a given "satisfaction unit".

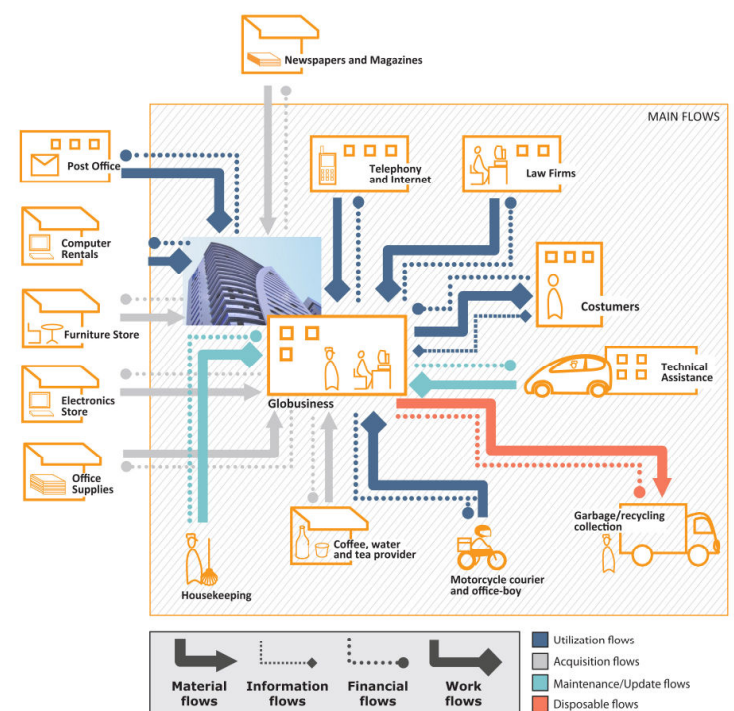

Figure 2. Polarity Diagram using cards with scenarios (Case Study Globusiness).

The use of the Polarity Diagram on the MSDS occurs on the phase of "Exploring Opportunities". However, the experience at NDS/UFPR have shown the need to bring this tool to the Strategic Analysis phase. Such approach happens due to the need for the organizations to understand the strategic implications of PSS and the choices that the organization will have to make (see next image). The best experiences on this tool involved the production of cards with scenarios. In such cards the company representatives can present their point of view by voting with circular stickers (red $=$ not possible; yellow $=$ difficult but possible, green $=$ possible).

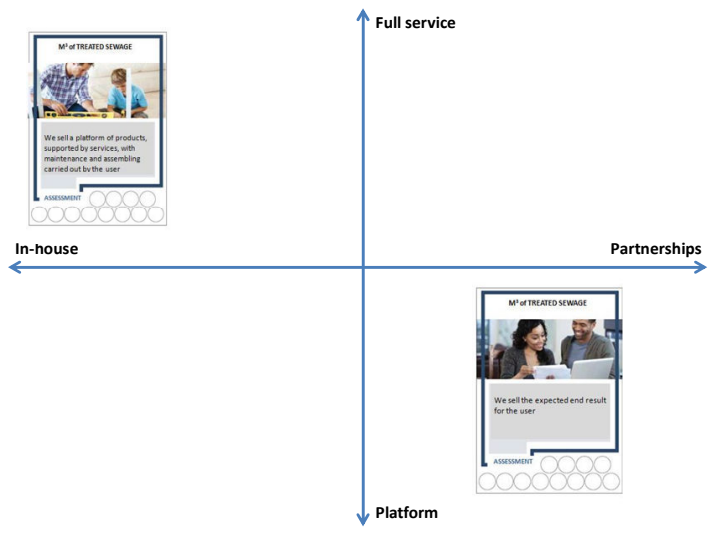

Figure 3. Polarity Diagram using cards with scenarios.

The case studies developed at NDS/UFPR have also extensively used Benchmarking, focusing on the "satisfaction unit" and looking into benchmark organizations in the same sector or, alternatively, benchmarks of other sectors with the provision of similar "satisfaction units". This Benchmarking provides the information to prepare the Service Distribution Map tool, where the company representatives present their 
perspective regarding the range of service that can (or will) be offered.

The tool enables the participants to "play" with a full range of possibilities of services, including those that already exist on the organization as well as those identified during the Benchmarking process. In one quadrant the participants place the services that would be provided by the company whilst in the other are those services that would be outsourced. Also, the participants need to show how direct is the relationship of these services with the users/clients.

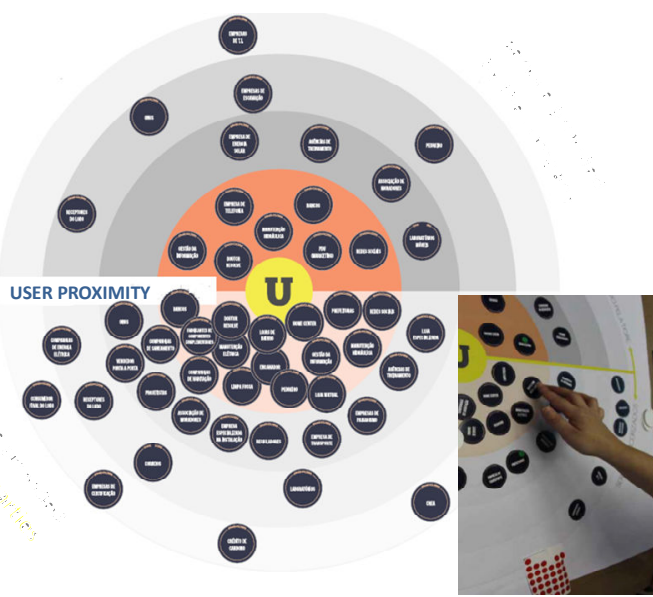

Figure 4. Service Distribution Map.

The Blueprint Tool structure also have shown to be quite useful on enabling a more empathic understanding on the long term implications of integrating new services on the organization. However, its conventional form is not easily understood and results in little empathy possibilities. Because of that in some exercises the research group has adopted the actual structure of a theatre as the background for the group dynamics (see next image).

Blueprint contributes to provoke a reflection on the organization regarding what would be the user activities; what would be in the line of visualization (onstage); which services would be on the backstage; which supporting services will be required. Also, it enables to envisage possible requirements of the PSS on workforce, equipments, softwares and other key points of contact.

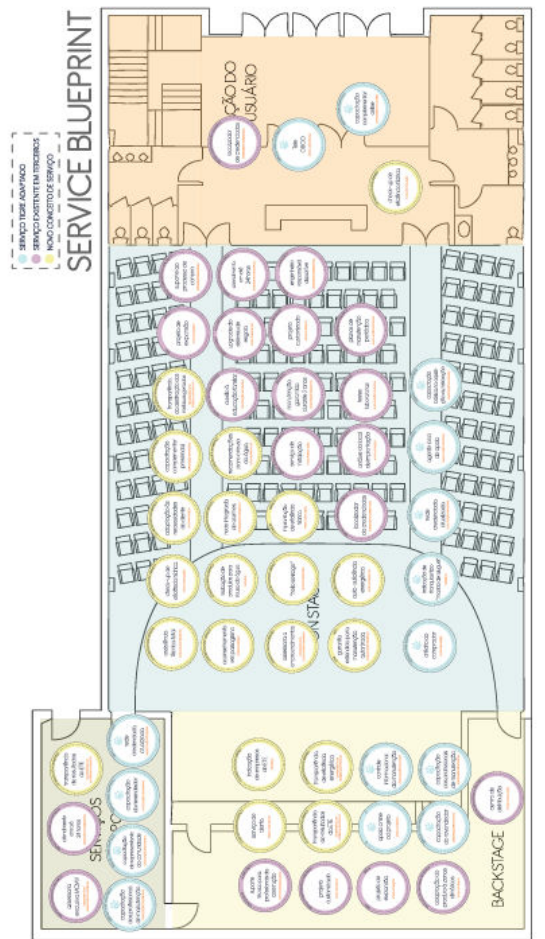

Figure 5. Theatre layout as an analogy for a Blueprint Exercise

However, the actual meaning of a PSS for the organization often is not fully understood and can result on poor strategic decisions. In order to facilitate this the researchers have widely use Storyboards, either using digital sketches or actual photos that provide the background of the places where the products/services would operate.

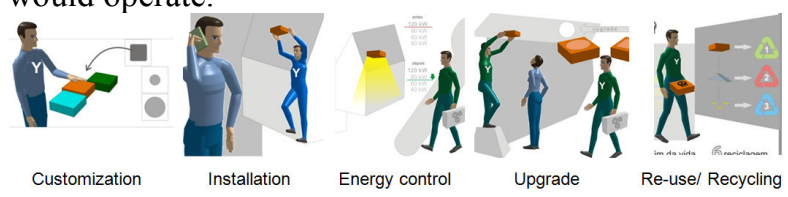

Figure 4. Storyboard of a Product-Service System concept.

In order to bring further realistic perception to the company regarding the market implications of new product/service offers, the researchers at NDS/UFPR have increasingly used the idea of a meta-PSS, a generic concept of a PSS, to establish a dialogue with the organization representatives. Next figure shows an example of a meta-PSS on the form a "fake folder" that exemplifies a scenario for a set of products and services. 


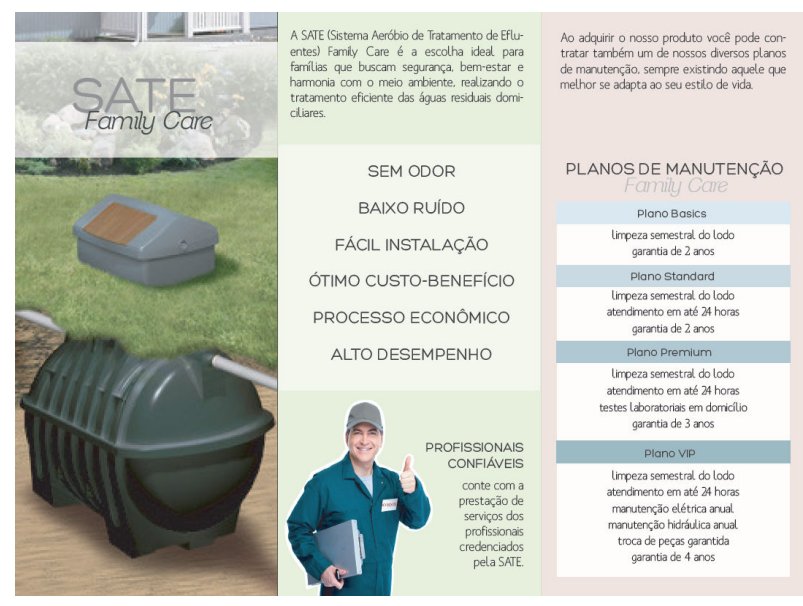

Figure 6. "Fake folder" as an instrument to establish a dialogue on the strategic implications of alternative PSS concepts.

Rough Service Prototypes, such as the one presented on the video illustrated on the next figure, can also be useful on this Strategic Analysis phase. This Design Science abductive approach uses artefacts (services/products) to gather the perspective of decision makers on long term issues. This technique (particularly when involving the actual decision makers on the rough prototype) enables a more emphatic discussion of issues such as the suitability of the new services derived from a PSS project on the company branding strategy; the need to bring on board new business partners on the project; the scope of the PSS regarding the company mission.

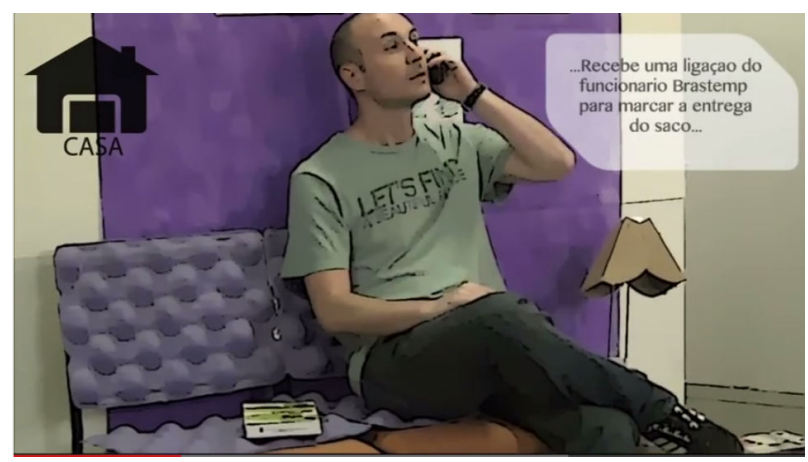

Figure 7. Rough Service Prototype ${ }^{\mathrm{a}}$ (Case Study Whirlpool).

The discussion on the strategic implications of the PSS can be discussed using the "Structured What If Technique (SWIFT)" which consists of structured brainstorming using guide words and prompts to identify risks and possible actions to mitigate them.

\section{CONCLUSION}

The projects developed at the Design \& Sustainability Research Center at UFPR have adopted a set of tools derived from administration as well as from

\footnotetext{
${ }^{\mathrm{a}}$ https://www.youtube.com/watch?v=qFiFRQAx0vs
}

Service Design which are not seen on the MSDS Method.

Table 1. Range of Tools for the Strategic Analysis Phase

\begin{tabular}{|l|l|l|}
\hline Tools & MSDS & NDS \\
\hline Strategic Elicitation Questionnaire & & \\
\hline ANSOFF matrix & & \\
\hline BCG matrix & & \\
\hline SLACK matrix & & \\
\hline SWOT matrix & & \\
\hline miniDOC & & \\
\hline System Mapc & & \\
\hline Porter's 5 Forces Model & & \\
\hline Benchmarking & & \\
\hline Preparatory company questionnaired & & \\
\hline Blueprint & & \\
\hline Customer Journey & & \\
\hline Service Distribution Map & & \\
\hline Touchpoint Matrix & & \\
\hline Rough Service Prototype & & \\
\hline Structured What If Technique (SWIFT) & & \\
\hline Exploring Customer Needse & & \\
\hline Sustainability Design-Orienting (SDO) \\
toolkitf-checklist best practice & & \\
\hline Interaction table (storyboard) & & \\
\hline Animatic & & \\
\hline DSE Worksheet 1: User observation \& \\
Task analysis flow chart & & \\
\hline DSE Worksheet 2 & & \\
\hline DSE Worksheet 3: (System Map) & & \\
\hline DSE Worksheet Tool & & \\
\hline
\end{tabular}

Integrating the tools derived from Service Design on the MSDS method proposed by VanHalen, Vezzoli and

${ }^{\mathrm{b}}$ For an example of a SWOT analysis, see the tool packet created during the MEPSS project

(http://www.mepss.nl/index.php?p=tool\&14=W05).

${ }^{c}$ A tool similar in purpose to the System map is the Actor network map. For further information see Morelli (2006a).

${ }^{\mathrm{d}}$ Created during the MEPSS research project (http://www.mepss.nl/index.php?p=tool\&14=W02).

${ }^{\mathrm{e}}$ Created during the MEPSS project

(http://www.mepss.nl/index.php?p=tool\&14=W17).

${ }^{\mathrm{f}}$ Another tool that can be used to analyse the sustainability

characteristics of a Product-Service System is the INES, Improving New Services, tool created during the 'Eco-efficient PSS' research project, funded by the Austrian Ministry of Transport, Innovation and Technology.

${ }^{\mathrm{g}}$ A tool similar in purpose to the Interaction table is the Use cases. For further information see Morelli (2006b). 
Wimmer (2005) (Blueprint, Touchpoint Matrix, Customer Journey) have shown on the case studies the benefit of increase the depth of the analysis, enabling a more emphatic Strategic Analysis.

Using a Design Science approach NDS/UFPR brought the phase of "exploring opportunities" of the MSDS Method into the Strategic Analysis phase. Understanding the possible implications of introducing new products/services on the company portfolio using meta-concepts enables decision makers to have a more comprehensive understanding on the strategic implications of PSS throughout the organization on the long term.

\section{Acknowledgments}

Acknowledgments to the Brazilian research funding agencies CAPES, CNPq and FINEP as well as to all business partners of NDS/UFPR (Volkswagen, Globusiness, Tigre, Cohapar, Whirlpool, Accord) on its venture to develop knowledge on PSS Design.

\section{References}

AMARAL, D. C. \& ROZENFELD, H. Integrating new product development process references with maturity and change management models. International Conference on Engineering Design, ICED 07, Cite Des Sciences et de L'Industrie, Paris, France, 2007.

ROBSON, C. \& McCARTAN, K. Real World Research, 4th Edition, Wiley, 2016.

ROZENFELD, H. . Reference model for managing product development. In: Günther Seliger. (Org.). Sustainability in Manufacturng. 1 ed. Berlim: Springer, 2007, v. , p. 193-206.

VEZZOLI, C.; KOHTALA, C.; SRINIVASAN, A.; DIEHL, J.C.; FUSAKUL, S. M.; XIN, L.; SATEESH, D. Product-Service System Design for Sustainability. Greenleaf, 2014.

YIN, R. Case Study Research: Design and Methods (Applied Social Research Methods), SAGE Publications, Inc; 4th edition, 2008. 